\title{
Defining Risk and the Use of Risk Assessments by Learning Specialists within NCAA Academic Units: An Exploratory Study
}

\author{
Lauren K. Birch, M.S. \\ Florida State University \\ Mary Anne Steinberg, Ph.D. \\ Virginia Polytechnic Institute and State University \\ Cheryl Walther, M.Ed. \\ Auburn University \\ Kellie A. Catanach, M.S. \\ Florida State University \\ Maria Herbst, Ph.D. \\ Clemson University \\ Jacqueline C. Perez, M.A. \\ Florida Atlantic University
}

\author{
Author Note \\ Thank you to Graduate Student, Department of Statistics, Institution \\ for assistance with statistical analysis
}

\begin{abstract}
Abstract:The National Collegiate Athletic Association (NCAA) (2009) defines the term "risk" as a "student-athlete's likelihood of graduation" (p. 2). The ability of athletic departments and athletic academic professionals to identify which of their student-athletes might be considered at risk is less straightforward. While many departments use their own tools to assess risk, there has been little research on the subject. This exploratory study sought to generate a collective understanding of how athletic academic units across the country define the term "at-risk" and assess which of their student-athletes are at-risk in order to begin creating a framework for use across the industry. A survey was completed by 43 members of the National Association of Academic and StudentAthlete Development Professionals (N4A) who serve in learning specialist roles within athletic academic units. The results showed that academic units, across NCAA institutions, do not have one clear definition of risk, but rather the definition falls into four distinct categories. The study also found that there are three initial risk assessments used most frequently to determine student-
\end{abstract}


athletes' risk upon arrival at the institution, while the continued risk assessments fall into six distinct categories of assessments. As this is an exploratory study, the researchers acknowledge that we are only scratching the surface in regard to the breadth and depth of assessment usage to determine risk of student-athletes at NCAA institutions. Therefore, the implications for future research are discussed.

Keywords: risk, assessment, initial assessment, continued assessment, student-athlete

As student-athletes arrive on college and university campuses, many are not prepared for the rigors of the college classroom. According to the Manhattan Institute for Policy Research, only $32 \%$ of all students who leave high school are ready for college (Horton, 2015). Lack of preparation may result in the students, including student-athletes, being at risk for academic difficulties. The Glossary of Education Reform defines at-risk as a term "used to describe individual students or groups of students who are considered to have a higher probability of failing academically or dropping out of school" (Horton, 2015, p. 83). The selection of factors to consider in determining which student-athletes are at-risk has historically been subjective in nature and has led to debates as to what actually deems a student-athlete to be considered at-risk within collegiate athletic academic units. Thus, it is important to generate a stronger understanding of student risk and the factors involved in identifying risk.

Standardized assessments such as the Scholastic Aptitude Test (SAT) and American College Testing (ACT), in addition to other state and federal assessments, are aimed at providing educators, administrators, and policy makers a baseline of each student's understanding around a set subject and its corresponding concepts. In addition to standardized assessments, a number of formative assessments are useful to educators, including those administered by learning specialists within athletic academic units. Both standardized and formative assessments are essential for educators to ensure that they are connecting students with appropriate resources.

Various factors may contribute to the number of student-athletes with potential risk factors, including the expansion of the Americans with Disabilities Act (ADA), more rigorous National Collegiate Athletic Association (NCAA) academic standards for continuing eligibility, and continuous competition in recruiting. While there are numerous assessments, such as the Nelson Denny Reading Test, Learning and Study Strategies Inventory (LASSI), Graduation Risk Overview (GRO), grade point averages (GPA), and informal skill assessments that can be used to determine the vast number of variables that may inhibit a student-athlete's academic success, many within the learning specialist profession are interested in knowing which initial and continued risk assessments are utilized most often at NCAA institutions. Currently, there is not a uniform standard assessment protocol consistently used to determine which student-athletes might be at risk for academic difficulties, as risk factors may vary from institution to institution. This exploratory study sought to determine how athletic academic units are defining risk at their respective institutions, what initial and continued assessments they utilize to determine risk, and if the academic units are using the NCAA Graduation Risk Overview as an assessment tool. 


\section{Factors Influencing the Increase in the At-risk Student Population}

Several factors may contribute to the increasing number of student-athletes who are considered academically at-risk. One factor is the greater number of college students with diagnosed disabilities, which is due in part to the expansion of the ADA from 2008. Through the expansion of the ADA, the federal definition and interpretation of disability criteria was broadened with the intention of "making it easier for an individual to establish that he or she has a disability" (Department of Justice, 2016, p. 53204). The broadened criteria in the ADA Amendment led to increased diagnoses for students and, in turn, has led to more students seeking accommodations on college campuses in general (Wolverton, 2016). This increase has translated into the academic areas of collegiate athletics as well, altering the support needed for student-athletes who meet accommodation eligibility criteria and leading to the growing need for learning specialists to support these students.

NCAA academic eligibility standards may have also led to an increase in the numbers of student-athletes identified as at-risk. This is due, in part, to more stringent NCAA academic eligibility standards that were enacted in 2003 "to maximize academic success" (Petr \& McArdle, 2012 , p. 34). In 2014, a new penalty structure was enacted, causing further pressure to maintain academic standards. These include benchmarks for progress toward degree, cumulative GPA, and completed credit hours. Bylaw 14.4.3.1 in the NCAA Division I Manual states that student-athletes must successfully complete at least $40 \%$ of their degree program's required coursework prior to their fifth semester of full-time enrollment. They must also complete at least $60 \%$ prior to their seventh semester of full-time enrollment, and at least $80 \%$ prior to their ninth semester of full-time enrollment (Meyer, 2005; NCAA, 2017). The NCAA Division I Manual also stipulates, in Bylaw 14.4.3.3, that a student-athlete's cumulative GPA must be $90 \%$ of the university's requirement for graduation at the start of their third full time semester, $95 \%$ at the start of their fifth full time semester, and $100 \%$ from the start of their seventh full time semester through graduation (NCAA, 2017). Finally, in the 2017-2018 NCAA Division I Manual, Bylaw 14.4.3.1 states that studentathletes must successfully complete 18 semester credit hours during the course of the two full time semesters preceding certification (e.g., fall and spring), and six semester credit hours during the course of the full-time semester preceding certification (e.g., fall; NCAA, 2017). This bylaw also states that freshmen student-athletes must successfully complete 24 semester credit hours prior to the start of their third full time semester. Certain sports have additional regulations with stricter standards for credit hour completion beyond these baseline minimum standards. NCAA benchmarks add additional challenges for students who may already struggle academically, which results in the student being labeled as "at-risk" by their institution.

\section{Literature Review}

\section{Assessing At-Risk Student-Athletes}

To adequately support student-athletes, it is important for learning specialists and athletic academic units to consider what type of assessments they are utilizing to determine the services the student-athlete will need in order to make adequate progress towards graduation and obtain "life-long achievement and success" (NCAA, n.d., p. 1). Assessing the risk level of studentathletes is not a new concept. According to Sanz and Whitner (1987), the University of Toledo sought to determine the initial risk of incoming student-athletes three decades ago in the 1980s. 
To do this, the University of Toledo's Athletes Educational Planning Program examined criteria such as ACT, SAT, high school preparatory courses, high school GPA, the college at which they enrolled, and the major area of study in order to determine which of their student-athletes were at moderate and high academic risk. Those students identified would need to meet with employees in the Counseling Center to learn academic and study skills. The researchers found that the support the program provided was beneficial for moderate risk students, and that higher risk students may need more specialized programming.

Many academic units utilize both academic criteria, such as GPA and high school transcripts, as well as holistic criteria, such as personal history, injury, mental health, and substance abuse, amongst other variables, in order to determine the risk of the student-athlete. Dennis, Phinney, and Chuateco (2005) studied the non-cognitive, cognitive, and demographic factors of 275 students who were entering college, 16 of whom were also part of an athletic team at the university. The study notes that variables such as race, socioeconomic status, and gender are important variables to consider in regard to academic success and retention. Sedlacek (2004) explains that variables such as adjustment to college, motivation, and the student's perceptions are also important non-cognitive factors to assess.

Due to the subjective nature of the term at-risk, NCAA athletic academic units, which are evaluating the risk of their student-athletes, may have varying definitions of risk depending on their institution. Taking region and school-specific factors into consideration can also prevent formulation of a uniform definition of risk. Robbins, Allen, Casillas, Hamme Peterson, and Le (2006) used a set of scales to determine student readiness in 10 specific areas: academic discipline, academic self-confidence, commitment to college, communication skills, emotional control, general determination, goal striving, social activity, social connection, and study skills. In this study of more than 14,000 students across 48 universities and colleges, the importance of considering multiple factors in predicting student preparedness was identified, with the recommendation to employ a combination of academic, social, self-management, and emotional factors. Results of the study indicated that academic discipline and general determination were the strongest factors predicting readiness, while the other factors did not have as much of an impact. In general, Robbins et al. (2006) suggest that "motivational factors, in particular academic-specific factors, can be measured in a way that predicts academic performance...[and] better predicted retention" (p. 612). The empirical uniformity constructed in this study contributes to a stronger understanding and definition in determining risk.

The NCAA (2009) referred to risk in relation to a "student-athlete's likelihood of graduation" when it established the Graduation Risk Overview (GRO) system as part of the Facilitating Learning and Achieving Graduation (FLAG) program (p. 2). The GRO system was developed by looking at data from a diverse set of risk factors identified as "potential barriers to graduation" from the following five categories: academic background/achievement, role of academics, transfer status, personal history, and sport-related issues (NCAA, 2009, p. 1). As evidenced by the categories of the GRO model and identified by Robbins et. al (2006), having a measure can help target issues beyond academics, since at-risk students can often have additional challenges impeding their success. 
The variance in risk was recognized by the NCAA in their research to establish an assessment standard. A study by Johnson (2013) aimed to determine if factors such as cumulative GPA, semester GPA, and demographic characteristics added to the predictive ability of the GRO. Coaches completed the GRO assessment for one identified student-athlete to determine the student-athlete's risk over two terms. Results showed that the GRO total and semester GPAs had "a relatively strong relationship" (Johnson, 2013, p. 81), indicating that a higher risk on the GRO assessment correlated with lower semester GPAs. Considering the all-encompassing variables, including subjective variables such as "student-athlete dissatisfied with athletics experience" (NCAA, 2009, p. 8), academic or non-subjective variables tend to show a higher rate of risk predictability, even when utilizing the GRO assessment (Johnson, 2013).

\section{Study Purpose}

Student-athlete academic support units are believed to utilize risk assessments in order to help them identify what qualifies student-athletes at their institution as at-risk and provide appropriate supports to mitigate risk. This exploratory study sought to determine how athletic academic units define risk and which risk assessments are being used at NCAA institutions. Survey research methodology was utilized in order to determine what assessments are used and by whom.

This exploratory study asked the following research questions:

1. How do NCAA athletic academic units define risk?

2. What initial risk assessment(s) are used to determine the risk of student-athletes within NCAA athletic academic units?

3. What continued risk assessment(s) are used to determine the risk of student-athletes within NCAA athletic academic units?

4. Is the NCAA Graduation Risk Overview (GRO) being used as a risk assessment tool within NCAA athletic academic units?

\section{Method}

\section{Participants}

Study participants were members of the National Association of Academic and StudentAthlete Development Professionals (N4A), previously referred to as the National Association for Academic Advisors for Athletics, who identified themselves as fulfilling the learning specialist role within their institution's athletic academic unit at campuses across the country. The participants were recruited based on the following criteria: (a) being members of N4A and (b) identifying themselves as being in the learning specialist's role, overseeing learning specialists, or those who had learning specialist duties at their respective institutions.

\section{Materials and Instrumentation}

In order to gather data from across the United States, a survey was developed by members of the N4A Learning Concerns and Enhancement Committee (LCEC). Prior to developing the survey, previous research about risk assessment utilization was reviewed. Based on the review of the existing literature, the members of the LCEC subcommittee determined that further research 
needed to be conducted regarding how athletic academic units define risk and which initial and continued risk assessments are being utilized at the post-secondary level within athletics. Therefore, a survey was created that consisted of a combination of 23 open and closed-ended questions. Questions in the survey were divided into the following five sections: demographic information, defining risk, initial risk assessment, continued risk assessment, and the efficacy of the risk assessments. The final version of the survey was disseminated to the N4A listserv in July of 2017 through Google Surveys (see Appendix A).

\section{Results}

Forty-three members of N4A across NCAA colleges and universities completed the survey. Appendix B contains demographic information about the survey respondents. Descriptive statistics were used to analyze the results of the survey. Qualitative analysis was utilized in order to interpret research questions one and three. For research questions one and three, two of the researchers took part in blind coding to determine how participants defined risk and which continued assessments are utilized by academic units. The researchers coded the survey responses independently and then spoke via phone to go through each line of text and compare codes. For research question one, the coders went through 39 lines of code, of which five lines could not be coded due to being unable to decipher the participants' response. Therefore, 34 lines of the participants' responses were able to be coded. They had an inter-coder reliability of $82 \%$. For research question three, the researchers looked at 34 lines of coding, in which two lines were not able to be coded. The coders had an intercoder reliability of $78 \%$. Due to low inter-coder reliability, the coders went back to recode and came back together approximately a week later to go through each line of coding again. On a second attempt, for research question one, the researcher had an inter-coder reliability of $82 \%$ and for research question three, they now had an inter-coder reliability of $97 \%$.

\section{Research Question 1}

How do NCAA athletic academic units define the risk of their student-athletes? The results, shown in Table 1, found that there were five major categories that learning specialists used to define risk within their academic unit. Within some major categories, the results indicated that there were subcategories and associated concepts for the subcategory. Although the question sought to determine how academic units define risk, many participants reported concepts that were associated with risk, as opposed to giving a single definition. However, one participant indicated that their unit does not have a clear definition of risk, while another participant indicated that their unit's definition was "concern that the student-athlete will not be retained or graduate without support." Through qualitative analysis, the survey determined that there is not one clear definition of risk, but rather there are factors that academic units look at when determining the risk of studentathletes with whom they work. Table 1 summarizes the coded responses. 
Table 1

Risk Defined

\begin{tabular}{|c|c|c|}
\hline Category & Sub-Category & Associated Concepts \\
\hline \multicolumn{3}{|l|}{ Academics } \\
\hline & GPA & $\begin{array}{l}\text { High school GPA, college } \\
\text { GPA, non-specific GPA, } \\
\text { quality points }\end{array}$ \\
\hline & $\begin{array}{l}\text { Academic History: High } \\
\text { School }\end{array}$ & $\begin{array}{l}\text { ACT scores, SAT scores, } \\
\text { high school rank }\end{array}$ \\
\hline & Academic History: College & $\begin{array}{l}\text { Low test scores, specially } \\
\text { admitted into university, } \\
\text { academic standing, course } \\
\text { load, difficulty of course } \\
\text { load, failing, eligibility } \\
\text { concern, withdrawals }\end{array}$ \\
\hline & Underprepared & $\begin{array}{l}\text { Low performing, skill } \\
\text { deficiency, academic } \\
\text { limitations, preparedness for } \\
\text { college work }\end{array}$ \\
\hline & Retention & Graduation concern \\
\hline \multirow[t]{3}{*}{ Screenings } & & $\begin{array}{l}\text { Internal assessments, self- } \\
\text { evaluations, placement tests, } \\
\text { student perception of support }\end{array}$ \\
\hline & Staff Input & $\begin{array}{l}\text { Interviews, meetings, tutor } \\
\text { and coach reports }\end{array}$ \\
\hline & Formal Assessments & $\begin{array}{l}\text { Nelson Denny, Accuplacer, } \\
\text { NCAA FLAG GRO }\end{array}$ \\
\hline Personal History & & $\begin{array}{l}\text { First generation, location, } \\
\text { family history, poverty, } \\
\text { medical concerns, homesick, } \\
\text { family problems, injury }\end{array}$ \\
\hline Behavior & & $\begin{array}{l}\text { Attitude, effort, social \& } \\
\text { emotional concerns }\end{array}$ \\
\hline Language Difficulties & & ESOL, international \\
\hline
\end{tabular}




\section{Research Question 2}

What initial risk assessment(s) are used to determine the risk of student-athletes within NCAA athletic academic units? As there is currently no uniform way to assess academic risk in both incoming and continuing student-athletes, each department utilizes their own methods for assessing risk, as verified by the vast categories, sub-categories, and associated terms found in the survey results. These assessments likely include the administration of one or a combination of different tools or surveys to assess risk. In order to analyze this, descriptive data were calculated (see Table 2).

Table 2

Initial Assessments Utilized to Determine Risk

\begin{tabular}{lrr}
\hline Utilize initial risk assessment & $\mathbf{N}$ & $\mathbf{\%}$ \\
Formal risk assessment & 40 & 93.0 \\
Informal risk assessment & 27 & 62.8 \\
Criteria & 16 & 37.2 \\
Academic and holistic criteria & & \\
Academic only & 35 & 81.4 \\
Holistic only & 4 & 9.3 \\
& 4 & 9.3 \\
Instruments used to calculate initial academic risk & & \\
ACT/SAT scores & & \\
High school transcripts & 40 & 93.0 \\
Academic history & 36 & 83.7 \\
Mental health inventories & 28 & 65.1 \\
Nelson Denny reading test & 17 & 39.5 \\
Scholastic Abilities Test for Adults (SATA) & 10 & 23.3 \\
Learning and Study Strategies Inventory (LASSI) & 6 & 14.0 \\
Test of English as a Foreign Language (TOEFL) & 5 & 11.6 \\
Wide Range Achievement Test (WRAT) & 5 & 11.6 \\
\end{tabular}

Note: Percentages do not add up to $100 \%$ due to rounding.

\section{Research Question 3}

What continued risk assessment(s) are used to determine the risk of student-athletes within NCAA athletic academic units? Similar to research question one, the qualitative analysis of research question three revealed that the assessments utilized to evaluate the continued risk of student-athletes fell into six broad categories, further broken down into five sub-categories with associated terms. The six major categories of assessments used to determine continued risk include: Academic History, Personal History, Assessments (formal and informal), Behavior, Diagnosis, and None. The qualitative survey results are listed in (Table 3). 
Table 3

Continued Assessments Utilized to Determine Risk

$\begin{array}{lll}\text { Categories } & \text { Sub-Category } & \text { Associated Terms }\end{array}$

Academic History

GPA

NCAA Standards

Personal History

Assessments

None
Behavior

Diagnosis

Formal Assessments

Informal Assessments

Staff Input
Academic standing, course load, course withdrawals, grades (past, current), difficulty of classes, online vs. ground classes, quality points, reports from professors, transcripts

College GPA, term GPA, cumulative GPA

Progress towards degree, eligibility

Aathletic injury, financial concerns, in season vs. out of season, personal obstacles, substance abuse

\section{SATA, LASSI, NCAA FLAG GRO}

Skill evaluation (benchmark or academic skill development), academic plans, student selfassessment, screening for deficient skills, interview with student, inhouse assessment, frequent meetings, student learning outcomes, upcoming course load

Coach input, advisor input, observations from advisors and learning specialists

Work ethic, attitude

Learning disability, ADHD, mental health

Restructuring program, readminister initial risk assessment 


\section{Research Question 4}

Is the NCAA Graduation Risk Overview (GRO) being used as a risk assessment tool within NCAA athletic academic units? Of those who responded, 65.9\% said they do not use the NCAA GRO and $34.1 \%$ said they did. According to the survey, $71.4 \%$ of participants had heard of the GRO, while only $34.1 \%$ of participants indicated that their academic unit uses some variation of the model. The GRO model provides adjustable overall subheadings of academic, personal, and sport. There is also an option in the GRO model to include other custom risk factors, which are set by the individual universities, and are appropriate based on the needs of the individual athletic academic unit and the university standards and/or policies. The GRO assessment provided by the NCAA recommends the use of initial and continuing assessments.

\section{Discussion}

Overall, the survey results indicated there is currently no known standard definition of risk or risk assessment measures that are utilized by athletic academic units. However, once an athletic academic unit defines risk or determines which factors they may use to deem a student-athlete atrisk at their institution, they generally assess the student-athletes using any number of initial and continued assessments, including a percentage of respondents who make use of the GRO as the only, or one of several, their assessment tool(s).

The learning specialist position continues to grow within NCAA academic units as indicated by the increase in learning specialist membership with the N4A. According to N4A membership data, those who listed their titles as "learning specialist" or "learning services" increased from 6.4\% (93 members) of the total N4A membership in 2013 to 8.94\% (173 members) in 2016 (A. Harraway, personal communication, December 10, 2017). Data on the number of learning specialists in the N4A prior to 2013 were not available. With the increase in the learning specialist presence at individual universities, the number of student-athletes deemed at-risk seems to have grown as well, perhaps due to the increase in the number of student-athletes who are specially admitted into the university and the demand for increases in graduation rates. With growing numbers, it is essential that athletic academic unit learning specialists are utilizing the most effective initial and continued risk assessments in order to effectively place student-athletes who are deemed at-risk at their respective institutions with the appropriate academic resources.

Encouragingly, a majority of survey respondents did indicate use of an initial and/or continuing risk assessment. Utilizing an initial assessment allows athletic academic units the ability to establish a baseline and account for the external factors that may likely contribute to institutional acclimation for each student-athlete. Continuing assessments provide a more empirical method to establish the progression of the student. Frequency of re-assessment is based on each program. The data revealed that $67.4 \%$ evaluate risk on a semester or quarterly basis. Regular re-assessment can be helpful to keep pace with the dynamism of a college student-athlete's life and the additional stressors created from being both an athlete and a student. 
The data suggest that both academic and holistic criteria are utilized when assessing the risk of student-athletes. While academic factors are an essential part of risk assessments, there are multiple other factors to take into account when evaluating a student, including mental health, international status, and personal history, as well as sport-related considerations (coaching change, early professional opportunity, unhappy with sport, etc.). These factors can be important to include as they can often influence academic performance.

It is not necessary for athletic academic units to start from scratch and create their own risk assessment model. The NCAA GRO, with 15 years of research behind it, has created an initial and continued risk assessment profile that allows for adjustments to fit each institution's individualized needs. In the current climate of competitive recruiting and stricter eligibility demands, studentathletes are facing challenges to academic success as they are admitted with skills that might not be equivalent to that of the general student population. However, it is important to select the appropriate risk assessments that meet the needs of the individual athletic academic unit and university, as this will provide the most accurate data to appropriately place student-athletes with resources to aid them in succeeding at the institution.

\section{Limitations of the Study}

The current study received 43 responses, which means less than half of the learning specialists within the N4A organization responded to the survey. The researchers requested that those who hold a learning specialist title or role within the academic unit at their institution complete the survey. Low response rates could be due to only one learning specialist from each academic unit responding to the survey, as opposed to each of the learning specialists within the academic unit responding. Therefore, survey results are limited to a small survey sample and may not accurately reflect all possible risk assessments used across the country. Other considerations for low response may be due to the learning specialist role in athletics still being fairly new, and having varying job descriptions within departments, as evidenced by the recent jump in learning specialist membership in N4A but almost no mention as a role by the NCAA.

\section{Implications for Future Research}

The results of the survey provide a surface-level exploration of risk assessment usage by athletic academic units at NCAA institutions, which can serve as an initial springboard for future inquiry and research. Since there is little research in this area specifically, several areas of further research remain. Evaluation of the efficacy of risk assessment, once uniform data is collected for a period of time, could contribute to filling the gap between risk assessment and research on methods and type of support provided, particularly in the context of other areas such as graduation rates, academic progress rates, student perceptions, and post-graduation employment. Additionally, evaluating a risk assessment framework like GRO would allow recommendations for adjustments and new considerations, as it was created approximately ten years ago. A more technical consideration to evaluate would be establishing a best practice recommendation for updates for the NCAA. 
Furthermore, for individuals like learning specialists, this could encourage further scholarship through data collection as well as exploration of the role and need of learning specialists within athletic academic units. Encouraging research on initial and continued risk assessment can ensure that the appropriate student-athletes are being placed on learning specialists' caseloads as well as provide a greater level of targeted, proactive support to the studentathlete population. Parties involved in the decision-making process and the process for which student-athletes are deemed at-risk itself may be an area for further exploration as well.

Typically, the learning specialist, the academic advisor, director, or some combination of the three positions determines which student-athletes are deemed at-risk within an athletic academic unit. Of survey participants, $48.8 \%$ indicated that the determination of whether a studentathlete is at risk is a collaborative effort. The stakeholders involved in the decision making process and the actual process for which student-athletes are deemed at-risk may be areas for further exploration.

\section{Conclusion}

The introduction and utilization of risk assessments is still fairly new among athletic academic units. Educational policy researchers remind us that it is important to not misidentify, construct, or assume risk based on factors such as race, socioeconomic background, ethnicity, or religion (Harry \& Klinger, 2006). However, one should be aware of the impact that these variables may have on the academic success of student-athletes. As such, it is important to note the objective of this study is not to encourage the compartmentalization or permanent classification of any individual. Rather, the intent of a risk assessment is meant to foster a confidential, internal conversation to offer an enhanced learning experience for student-athletes by pairing them with resources for support as appropriate during their college career. The current study did not seek to make generalizations about the use of initial and continued risk assessments, but rather sought to determine which initial and continued risk assessments are used most often within the NCAA academic units, as well as determine if those units are utilizing the NCAA GRO as an assessment tool.

Academic risk assessments are tools which can provide a representation of a studentathlete's risk at any point aforementioned, including initial entry to an institution. The use of assessments can aid in transforming subjective variables like mental wellness into empirical data and combine it with objective data such as GPA. Although not a perfect model, the GRO can be helpful for those involved in developing academic plans for student-athletes. The authors view risk assessments as viable tools to provide learning specialists and other athletic academic unit staff with a method to ensure that student-athletes deemed at-risk are provided the necessary support and resources. It can also be a constructive tool for learning specialists in establishing caseloads and encouraging conversation and collaboration among colleagues. Additionally, employing a risk assessment may provide a degree of uniformity in support among the multiple academic parties interacting with student-athletes. Of the survey participants, $28.8 \%$ said that the determination of risk is a collaborative effort, mostly between the learning specialist, advisor, or another relevant party (e.g., coach, director, etc.). It is important that athletic academic staff members who work with the student-athlete, whether it be in an advisor and/or learning specialist capacity, are in agreement regarding which assessments are used in order to streamline the process of determining risk at their respective institutions. 
The information provided from risk assessments may in turn provide a degree of professional development for staff not familiar with areas of concern. Furthermore, it may also provide guidance to target areas of challenge, which can be incorporated into academic plans for the student-athlete. Robbins et. al. (2009) pointed out that little research exists regarding the correlation to risk and use of resources. This exploratory study seeks to start this inquiry.

Although utilization of assessments is not a new method of evaluation in education, determining and defining the academic risk of student-athletes is not widely understood at this time. Initial risk can be assessed upon entry to an institution and continuing assessments can be provided as follow ups to monitor progress. Such assessments provide a foundation and real-time updates to adjust strategies as needed in a fast-paced environment like athletics.

Finally, this study is meant to serve as a step toward establishing standards and understanding for determining the risk of student-athletes and how their risk determines their support placement, since many student-athletes deemed at-risk are assigned to a learning specialist's caseload. Depending on the institution and the ratio of learning specialists to "at-risk" student-athletes, many learning specialists are becoming overworked with caseloads larger than what would allow them to effectively impact the student-athletes with whom they are working. Due to the fact that the learning specialist is often not the only person weighing in on which student-athletes are assigned to them, it is increasingly important that learning specialists, in conjunction with other members of their academic units, determine the key risk factors appropriate to their institution and risk assessments. 


\section{References}

Dennis, J.M., Phinny, J.S., \& Chuateco, L.I. (2005). The role of motivation, parental support and peer support in the academic success of ethnic minority first-generation college students. Journal of College Student Development, 46(3), 223-236. http://doi.org/10.1353/csd. 2005.0023

Department of Justice. (2016, August 11). Government publishing office. Retrieved July 23, 2017, from https://www.gpo.gov/fdsys/pkg/FR-2016-08-11/pdf/2016-17417.pdf

Educational Testing Services. (2018). The TOEFL test. Retrieved from ETS: https://www.ets.org/toefl

Harry, B. \& Klinger, J. (2006). Why are so many minority students in special education? Understanding race \& disability in schools. New York, NY: Teachers College Press.

Horton, J. (2015). Identifying at-risk factors that affect college student success. International Journal of Process Education, 83-102.

Johnson, J. (2013). Assessing academic risk of student-athletes: Applicability of the NCAA graduation risk overview model to GPA. NACADA Journal, 76-89. https://doi.org/ 10.12930/NACADA-13-041

Meyer, S. K. (2005, October). NCAA academic reforms: Maintaining the balance between academics and athletics. In Phi Kappa Phi Forum (Vol. 85, No. 3, p. 15). National Forum: Phi Kappa Phi Journal.

National Collegiate Athletic Association. (n.d.). Playing rules goals and objectives. Retrieved from http://www.ncaa.org/playing-rules/playing-rules-goals-and-objectives

National Collegiate Athletic Association. (2009). Graduation risk overview. Retrieved July 18, 2017, from https://web1.ncaa.org/GRO/pages/pdf/gro_educate.pdf

National Collegiate Athletic Association. (2017). 2017-2018 NCAA division I manual. Retrieved from: http://www.ncaapublications.com/productdownloads/D118.pdf

Petr, T. A., \& McArdle, J. J. (2012). Academic research and reform: A history of the empirical basis for NCAA academic policy. Journal of Intercollegiate Sport, 5, 27-40. doi: 10.1123/jis.5.1.27

Robbins, S., Allen, J., Casillas, A., Akamigbo, A., Saltostall, M., Campbell, R.,...Gore, P. (2009). Associations of resources and service utilization, risk level, and college outcomes. Research in Higher Education, 50, 101-118. https://doiorg.ezproxy2.library.colostate.edu/10.1007/s11162-008-9106-7

Robbins, S., Allen, J., Casillas, A., Hamme Peterson, C., \& Le, H. (2006). Unraveling the differential effects of motivational skills, social, and self-management measures from traditional predictors of college outcomes. Journal of Educational Psychology, 98(3), 598-616. doi:10.1037/0022-0663.98.3.598 
Sanz, D. L., \& Whitner, P. A. (1987). A study skills program for student-athletes. Paper presented at American Association for Counseling and Development Annual Convention (pp. 21-25). New Orleans, LA.

Sedlacek, W. E. (2004). Why we should use noncognitive variables with graduate and professional students. The Advisor: The Journal of the National Association of Advisors for the Health Professions. 24(2), 32-39.

Wolverton, B. (2016). The hottest hire in athletics? Learning specialists. The Chronicle of Higher Education, 62(25), A14, Retrieved from https://www.chronicle.com/article/TheHottest-Hire-in-Athletics-/235513 


\section{Appendix A}

\section{Use of Assessments to Determine a Student-Athlete's Risk}

Recent discussions within the Learning Concerns and Enhancements Committee (LCEC) within the National Association of Academic Advisors for Athletics (N4A) have shown a need for examining the use of risk assessments among Learning Specialists. A subcommittee of the Learning Concerns and Enhancement Committee is seeking information regarding the use of assessments that determine the initial and/or continued "risk" of student-athletes and how the assessment of risk(s) determines their placement on a Learning Specialist's caseload.

I am asking that current Learning Specialists participate in a brief survey about how their academic program defines risk for student-athletes, who determines if the student-athlete is at risk, what assessments, if any are used, and how risk assessments are used to place studentathletes on Learning Specialist's caseloads or with other educational services.

This research survey is voluntary and should take about 10 minutes to complete; you may discontinue participation at any time. Your responses will be anonymous to the maximum extent allowed by law. Survey data will be stored in Google Form, which is password protected. Only the primary investigator will have access to the raw data and the password used to obtain the results of the survey.

Overall, there is minimal risk in participating in this survey, and appropriate steps will be taken to ensure that individual responses are kept confidential, to the maximum extent allowed by law. By participating in this survey, you may or may not benefit.

Benefits of participation include increased awareness about the use and types of risk assessments that are utilized across the country by current Learning Specialists. The results of the survey may help current and/or future Learning Specialists enhance their Learning Support Programs. Additionally, the results of the survey may have future benefits for members of the N4A professional organization; including advisors and directors in athletic academic departments throughout the country. The results may assist Learning Specialists, Advisors and Directors in their understanding of different types of assessments used to identify risk factors that may lead to decreased retention and graduation rates of student-athletes. Identification of the risk factors, through assessments, may aid in providing appropriate academic services in order to increase retention and graduation rates.

If you have questions about this survey, please contact author at phone number or by email at email address. You may also contact Director by phone at phone number or by email address.

If you have questions or concerns about your rights as a participant is this research survey you may also contact the University IRB Office at Human Subjects Office Address, Phone Thank you for your time, and should you choose to participate, your honest feedback is greatly appreciated.

Thank you in advance for your time.

Author 
Mark only one oval.

- Yes, by clicking "Yes" you have read the above statement, printed a copy of this statement for your records, and agree to participate in the study.

- No Stop filling out this form.

\section{Academic Staff and Institution Information}

What Division is your Institution? Mark only one oval.

- Division I

- Division II

- Division III

- NAIA

- NJCAA

- Other:

What position do you hold within your athletic academic unit?

Mark only one oval.

$\circ \quad$ Learning Specialist

- Academic Advisor

- Tutorial Coordinator

- Director

- Hybrid Role (Advisor/Learning Specialist, etc.)

- Other

How many full-time people are on staff in your academic unit?

Mark only one oval.

○ $1-5$

○ 5-10

- $10-15$

- More than 15

How many full-time staff members serve as a Learning Specialist or have Learning Specialist responsibilities?

Across all sports, how many student-athletes are on Learning Specialists' caseloads within your academic unit?

What is the average number of student-athletes that are on each Learning Specialists' caseload on your staff? 


\section{Defining "Risk"}

Does your department use some type of assessment(s) to determine the initial and/or continued "risk" of a student-athlete?

Mark only one oval.

- Yes

- No

Who is the primary decision maker that determines whether a student-athlete is "at risk"? Mark only one oval.

$\circ$ Learning Specialist

- Advisor

- Director

- Administration

- Collaborative Effort

- Other:

How does your academic unit define risk?

Are you the primary decision maker that determines whether a student-athlete is "atrisk"? Mark only one oval.

- Yes

○ No

If you are not the primary decision maker that determines whether a student-athlete is "atrisk", how involved are you in the process? 


\section{Initial Risk Assessment}

Does your academic unit do an initial risk-assessment(s) to determine if a student-athlete needs to be placed with a Learning Specialist upon initial arrival at the institution?

Check all that apply.

- Yes, we use a formal assessment(s)

- Yes, but it is an informal assessment(s)

- No assessment(s) is used

When assessing a student-athlete's initial risk does your department look at academic and/or holistic criteria?

Mark only one oval.

- Academic criteria

- Holistic criteria

- Combination of academic and holistic

- Other:

What type of risk assessment(s) does your department utilize when initially assessing a student-athletes risk?

Check all that apply.

- High school transcript

- SAT/ACT scores

- Academic history inventory

- Mental health inventory

- Nelson Denny

- WRAT

- SATA

- LASSI

- TOFEL

- NCAA GRO (Graduation Risk Overview)

- We do not have a formal risk assessment

- Other:

If your department uses some type of risk assessment(s), does the department also have a tiered system of services (Learning specialist, mentor, tutoring, etc.) that students are placed into, depending upon their risk? Mark only one oval.

- Yes

- No

- We don't have an assessment for determining risk in place at this time 


\section{Continued Risk Assessment}

If a student-athlete is on a Learning Specialist's caseload how often does your department continue to assess their risk? Mark only one oval.

- Once every semester or quarter

- Once every year

- We only do an initial risk assessment

- We do not have a formal risk assessment in place

When assessing a student-athlete's continued risk does the department look at academic and/or holistic criteria? Mark only one oval.

- Academic criteria

- Holistic criteria

- Combination of academic and holistic

- Other:

What specific assessment(s) does your department use to assess a student-athlete's continued academic risk? Please list assessments or criteria used

\section{Is the use of a risk assessment(s) effective?}

Does your department measure the effectiveness of the risk assessment(s) used?

Mark only one oval.

- Yes

- No

- Not Sure

- Other:

Are the risk assessment(s) used in your academic unit effective in terms of determining Learning Specialists' caseloads?

Mark only one oval.
- Yes
- No
- Somewhat
- Other:

If your department does NOT have risk assessment(s) in place, is your program contemplating using risk assessment(s) in the future? Mark only one oval.
- Yes
- No
- Not Sure
- Other:

Has your department heard of the NCAA GRO (Graduation Risk Overview)? Mark only one oval.
- Yes
- No 
Does your academic unit use some variation of the NCAA GRO (Graduation Risk Overview)? Mark only one oval.

- Yes

- No

Please share any additional information about your department's use of risk assessments and Learning Specialist caseloads. 
Table 4

Appendix B

Demographic Information

Percentages

Athletic Division of Institution

Division I

$97.7 \%$

Division II

$2.3 \%$

Position Held at Institution

Learning Specialist

$62 \%$

Hybrid Role (Advisor/Learning Specialist)

$23 \%$

Director

$6.9 \%$

Full-Time Staff Members in Academic Unit

$1-5$

$18.6 \%$

$5-10$

$30.2 \%$

$10-15$

$30.2 \%$

15 or more

$20.9 \%$

Number of Full-Time Learning Specialists on Staff
$1-2$
3
4
5
$60.4 \%$
$18.5 \%$
$4.7 \%$
$11.6 \%$ 